\title{
Riesgos y complicaciones durante la sedación para endoscopía diagnóstica del tubo digestivo sin enfermedad concomitante
}

\author{
Risks and complications during sedation for \\ diagnostic endoscopy of the gastrointestinal \\ tract without concomitant disease
}

Dr. Baruvi Gaytán-Fernández*

Citar como: Gaytán-Fernández B. Riesgos y complicaciones durante la sedación para endoscopía diagnóstica del tubo digestivo sin enfermedad concomitante. Rev Mex Anestesiol. 2021; 44 (3): 200-206. https://dx.doi.org/10.35366/99667

RESUMEN. Durante la sedación en procedimientos endoscópicos del tubo digestivo alto y bajo, es frecuente que se susciten complicaciones ventilatorias y hemodinámicas. Se presenta una revisión de las estrategias para prevenir y tratar las complicaciones ventilatorias más frecuentes: espasmo laríngeo, apnea por fármacos anestésicos endovenosos y broncoespasmo. También se revisan las complicaciones hemodinámicas: reflejo vagal e hipotensión aguda. Se propone un algoritmo de manejo que sintetiza y esquematiza las medidas profilácticas y terapéuticas descritas en la literatura, ordenándolas de acuerdo a su prioridad y eficacia, permitiendo identificar con claridad el nivel de tratamiento necesario y la viabilidad del procedimiento endoscópico.

ABSTRACT. During sedation in endoscopic procedures of the lower and upper digestive tract, it is common for ventilatory and hemodynamic complications to arise. This article presents a review of the strategies to treat and prevent the most common ventilatory complications: laryngeal spasm, apnea due to intravenous anesthetic drugs and bronchospasm. Hemodynamic complications are also reviewed: vagal reflex and acute hypotension. A management algorithm is proposed which synthesizes and schematizes the prophylactic and therapeutic measures described in the bibliography, ordering them by their priority and effectiveness, allowing to clearly identify the degree of treatment necessary and the viability of the endoscopic procedure.

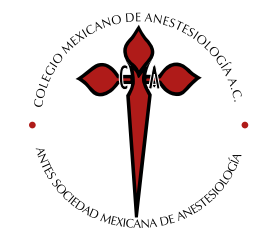

Palabras clave: Sedación, endoscopía, espasmo laríngeo, apnea por fármacos, broncoespasmo, reflejo vagal, hipotensión aguda.

Keywords: Sedation, endoscopy, laryngeal spasm, drug-induced apnea, bronchospasm, vagal reflex, acute hypotension.

* Anestesiólogo cardiovascular adscrito al Hospital General de Zona No. 50, IMSS. San Luis Potosí, SLP.

Correspondencia:

Baruvi Gaytán-Fernández Francisco Peña Núm. 1255, Col. Las Águilas, 78260.

San Luis Potosí, SLP.

Teléfono: (44) 4840-3159.

E-mail: dr.baruvi@yahoo.com

Recibido: 05-11-2019

Aceptado: 21-07-2020

\section{INTRODUCCIÓN}

E $\mathrm{n}$ los procedimientos anestésicos actuales indicados para las intervenciones endoscópicas, existen retos peculiares que no se encuentran en la práctica anestésica realizada en quirófano. Algunas de estas características incluyen: procedimiento ambulatorio, período anestésico corto pero con exigencia de sedación y analgesia profunda, acceso a vía aérea superior obstruido, procedimiento fuera de quirófano y alteración hemodinámica súbita.

Estos aspectos desencadenan un repertorio particular de riesgos y complicaciones durante la anestesia del procedimiento endoscópico que requieren una especial terapéutica actualizada y adecuada a las condiciones del área física, del procedimiento y de las limitaciones técnicas.

En este artículo se revisarán los aspectos que generan las complicaciones y riesgos ventilatorios y hemodinámicos más frecuentes durante la anestesia para el procedimiento endoscópico (panendoscopía y colonoscopía) en el paciente sin enfermedad agregada.

\section{PRESENTACIÓN}

Las complicaciones más frecuentes durante la anestesia del procedimiento endoscópico se pueden dividir en dos grupos: complicaciones ventilatorias (espasmo laríngeo, apnea por fármacos anestésicos endovenosos, broncoespasmo) y complicaciones hemodinámicas (reflejo vagal, hipotensión aguda).

\section{COMPLICACIONES VENTILATORIAS}

\section{Espasmo laríngeo}

El espasmo laríngeo es una exageración del reflejo normal de cierre glótico que persiste tiempo después de la desaparición del estímulo ${ }^{(1)}$. Durante el espasmo laríngeo se produce una 
fuerte y mantenida contracción refleja de toda la musculatura laríngea en respuesta a una estimulación intensa del nervio laríngeo superior, y aunque tiene una función protectora, produce obstrucción de la vía aérea en diferentes $\operatorname{grados}^{(2)}$. Este estímulo físico puede ser causado directamente por la saliva, secreciones o sangre, o durante la manipulación de la boca, nariz, faringe, laringe y la zona abdominal superior, en presencia de anestesia superficial ${ }^{(3)}$. El espasmo laríngeo parcial permite cierto movimiento del aire y es posible confundirlo con otras causas de obstrucción de las vías respiratorias altas; en cambio el laringoespasmo completo impide todo movimiento de aire y, además de causar hipoxia grave, es una causa importante de edema pulmonar por presión negativa ${ }^{(4)}$.

El tratamiento del espasmo laríngeo engloba tres objetivos: suspender el estímulo, inhibir el reflejo y restablecer la perfusión aérea.

Para conseguir estos objetivos, en este artículo se recomiendan una serie consecutiva de estrategias terapéuticas con un orden explícitamente sugerido, y por el grado crecientemente invasivo de las mismas, el éxito en alguna de las maniobras suspenderá a las subsecuentes. Luego del redactado se presentará un algoritmo que sintetiza y esquematiza todos los puntos que a continuación se describen.

1. Profilaxis. La lidocaína es un anestésico que inhibe el flujo iónico del sodio necesario para la transmisión del impulso nervioso, esto disminuye la frecuencia e intensidad de varios reflejos, incluidos los de protección laríngea. Previo al inicio de la sedación, se puede administrar de 1-2 mg/ $\mathrm{kg}$ de lidocaína IV, ayudando así a disminuir la activación del reflejo laríngeo.

2. Retirar estímulo físico.

a. Alejar panendoscopio de la zona laríngea.

b. Aspirado estricto de secreciones por nariz y boca.

3. Ventilación con mascarilla facial. Se administra oxígeno al $100 \%$ con presión teleespiratoria positiva o con presión positiva continua en la vía respiratoria que actúa a modo de férula neumática.

4. Maniobra de Larson. A la ventilación con mascarilla facial se le debe agregar una pulsión mandibular forzada con presión digital bilateral sobre el cuerpo de la mandíbula justo por delante de la apófisis mastoides. Esta maniobra puede resolver el laringoespasmo al despejar la vía respiratoria y estimular al paciente ${ }^{(5)}$.

5. Profundización de la sedación. La mayoría de los espasmos laríngeos suceden durante la anestesia superficial, por lo tanto se debe profundizar el grado de la escala de sedación. El medicamento más adecuado para este fin es el propofol debido a que su acción inhibidora de los canales de calcio también contrarrestará la actividad muscular de la que depende el espasmo laríngeo. Se recomienda una dosis en bolo de $1-2 \mathrm{mg} / \mathrm{kg}$.
6. Relajación muscular e Intubación endotraqueal. Si aun con todas estas maniobras no se ha restaurado la perfusión aérea, se debe reconocer la emergencia en el procedimiento y proceder a la intubación de la tráquea previa relajación muscular. Para este apartado, se puede utilizar succinilcolina; sin embargo, ante el riesgo de espasmo muscular agregado que ofrece este fármaco (especialmente en el músculo masetero), se puede utilizar bromuro de rocuronio, el cual es un relajante muscular no despolarizante que también ofrece un rápido inicio de acción (sólo 30 segundos más tarde que la succinilcolina) sin el inconveniente de la reacción muscular exagerada.

7. Realización del procedimiento. Una vez asegurada la vía aérea, y sin alguna otra contraindicación, se puede realizar el procedimiento endoscópico.

8. Extubación. Para evitar la recidiva del espasmo laríngeo al momento de la extubación se pueden aplicar las siguientes estrategias:

a. Aspirado estricto de secreciones.

b. Extubación durante la anestesia profunda o con el paciente despierto.

c. Una nueva aplicación de lidocaína IV.

d. Aplicación de sulfato de magnesio IV a razón de 10-15 $\mathrm{mg} / \mathrm{kg}$.

e. Asistencia ventilatoria con oxígeno al $100 \%$ a través de mascarilla facial.

f. Maniobra de Larson.

\section{Apnea por fármacos}

Entre los fármacos más usados durante la sedación se encuentran las benzodiacepinas, los opioides y el propofol; estos medicamentos tienen un proceso común en su farmacodinamia, causan apnea. Por separado, cada grupo de fármacos genera un periodo determinado de depresión ventilatoria y/o apnea; sin embargo, ya hace varias décadas se describió que la administración en conjunto puede provocar un incremento en el tiempo de esta complicación ${ }^{(6)}$, pudiendo ser superior a los cinco minutos. Se ha observado que la duración de la apnea varía de acuerdo a dos factores: la dosis y la velocidad de administración del fármaco ${ }^{(7)}$. Por ende, estos mismos factores se pueden utilizar como profilaxis para la depresión ventilatoria y/o apnea. El manejo de la apnea causada por anestésicos endovenosos puede llevar el siguiente orden:

1. Profilaxis. La administración fraccionada y lenta de la dosis ponderal disminuye considerablemente la depresión ventilatoria e incluso puede evitar la aparición de apnea. Esta sencilla pero efectiva estrategia puede cambiar el panorama completo del procedimiento ya que las ventajas que ofrece pueden ir desde disminuir tiempos de espera hasta evitar maniobras complementarias. 
2. Permeabilidad de la vía aérea. Para evitar confundir la apnea causada por anestésicos endovenosos con obstrucción anatómica de la vía aérea, se puede implementar el uso de instrumentos que la permeabilicen, como las cánulas nasofaríngeas flexibles o las cánulas orofaríngeas con canal de inserción para panendoscopio.

3. Asistencia ventilatoria. En caso de cualquier signo de depresión ventilatoria se debe asistir con $\mathrm{O}_{2}$ al $100 \%$ por mascarilla facial. Dependiendo del tipo de procedimiento endoscópico se pueden adoptar las siguientes conductas:

a. Panendoscopía. La asistencia se debe mantener hasta que el paciente recupere el ritmo y volumen ventilatorio adecuado. Una vez conseguido esto se puede iniciar el procedimiento endoscópico.

b. Colonoscopía. Ya que este procedimiento permite la accesibilidad completa a la vía aérea, se puede iniciar la colonoscopía mientras aún se está dando asistencia ventilatoria y esperar a que se reactive la ventilación normal del paciente durante el desarrollo del procedimiento endoscópico. De esta forma se disminuye el tiempo de espera, el tiempo de colonoscopía y los requerimientos de anestésicos endovenosos.

\section{Broncoespasmo}

El músculo liso en la vía respiratoria se extiende hasta los bronquiolos terminales y se ve afectado por la actividad del sistema nervioso autónomo y por mecanismos no adrenérgi$\cos$, no colinérgicos ${ }^{(8)}$. Los nervios parasimpáticos originados en centros vagales del sistema nervioso central determinan el tono basal y la broncoconstricción refleja mediado por cambios en la sensibilidad al calcio y su flujo al interior de la célula ${ }^{(9)}$. Es por eso que los inhibidores de la movilización del calcio (como el Propofol) pueden disminuir la respuesta constrictora bronquial del músculo liso.

Los pacientes con antecedente de asma utilizan con frecuencia medicamentos inhalados como $\beta$-agonistas, anticolinérgicos y corticosteroides en su tratamiento habitual, así como en los periodos de crisis $^{(10)}$. Estos periodos son exacerbados por reacciones alérgicas mediadas en parte por la liberación de histamina. Los opioides que se administran por vía endovenosa pueden inducir la activación de las células cebadas y producir liberación de histamina ${ }^{(11)}$.

Durante la sedación en endoscopía, el broncoespasmo no es un proceso exclusivo de los pacientes con asma, sino que se puede presentar como un efecto secundario de la liberación de histamina causada por los opioides, lo cual en este caso específico evidencia la necesidad de inhibir por vía endovenosa la liberación de histamina y no sólo administrar broncodilatadores inhalados. Para este objetivo, en este artículo se sugiere el siguiente esquema:
1. Profilaxis. Si el paciente presenta antecedentes de asma, es recomendada la profilaxis con el preparado inhalado que utiliza habitualmente.

2. Asistencia ventilatoria. En caso de cualquier signo de broncoespasmo se debe asistir con $\mathrm{O}_{2}$ al $100 \%$ por mascarilla facial y presión positiva.

3. Medicación inhalada. Si el paciente no tuviese antecedentes de asma, la primera línea de medicación inhalatoria recomendada es el preparado de $\beta$-agonistas combinado con un agente anticolinérgico más ipratropio ${ }^{(12)}$.

4. Medicación endovenosa. Esta modalidad de tratamiento se puede utilizar tanto para subyugar la crisis de broncoespasmo como para prevenir su reaparición.

a. Inhibidores de canales de calcio. El propofol induce broncodilatación y atenúa la broncoconstricción inhibiendo la vía de transducción de señal acoplada a receptores mediante la inhibición de la movilización del calcio $^{(13)}$. El propofol es el calcioantagonista de elección en estos procedimientos, ya que al mismo tiempo que broncodilata genera inductosedación.

b. Antihistamínicos. Es recomendable una inhibición selectiva de receptores H1. Una opción adecuada y accesible en casi todos los hospitales de la República Mexicana es el clorhidrato de cloropiramina a 0.2-0.3 $\mathrm{mg} / \mathrm{kg}$.

c. Corticosteroides. Se requiere administrar una combinación de esteroides de acción corta (por su rápido inicio de acción) con los de acción intermedia (por su mayor vida media). Una combinación adecuada puede ser hidrocortisona de $2-4 \mathrm{mg} / \mathrm{kg}$ y metilprednisolona de $1-2 \mathrm{mg} / \mathrm{kg}$.

d. Catecolaminas. Por su intensa acción $\beta$-agonista, en la broncoconstricción exacerbada que puede poner en peligro la vida, está claramente indicada la administración de epinefrina endovenosa $100-200 \mu \mathrm{g}$ en bolo ${ }^{(12)}$.

5. Intubación endotraqueal y manejo crítico. Si a pesar de la terapéutica descrita el cierre bronquial sigue siendo crítico, se debe administrar un relajante muscular y realizar intubación endotraqueal. También se debe iniciar el protocolo de maniobras de emergencia para preservación vital. Este es uno de los pocos casos en que la suspensión del procedimiento endoscópico está justificada.

\section{COMPLICACIONES HEMODINÁMICAS}

\section{Reflejo vagal}

Se conoce como reflejo vagal a la estimulación del sistema parasimpático a través del nervio vago que se caracteriza por la disminución súbita e intensa de la frecuencia cardíaca. Las causas que desencadenan este reflejo son múltiples: dolor severo, cambio de presión intraocular, estimulación del seno 
carotídeo, maniobra de Valsalva, estimulación bronquial, y por supuesto la estimulación del tubo digestivo en sus diferentes porciones, entre otras causas. Durante la endoscopía del tubo digestivo las causas más frecuentes de reflejo vagal son: la estimulación de los esfínteres y la distención súbita de víscera hueca. Esto genera una estimulación parasimpática intensa que se refleja clínicamente como bradicardia súbita y severa, con la disminución consecuente de las constantes vitales dependientes de la frecuencia cardíaca. Para contrarrestar los efectos del reflejo vagal, se pueden considerar las siguientes estrategias:

1. Cese del estímulo. Habitualmente el estímulo es causado por el endoscopio o por alguna de las maniobras realizadas con éste. El estímulo se puede presentar en diferente intensidad y por consecuencia el cese del estímulo deberá ser realizado en la misma proporción.

a. Estímulo por maniobra. Se refiere al avance, angulación, presión o cualquier movimiento causado con el endoscopio dentro del tubo digestivo. El estímulo en la gran mayoría de los casos cederá con la suspensión temporal de la maniobra.

b. Estímulo por insuflación. Sucede cuando se ha coleccionado dentro del tubo digestivo una cantidad de aire insuflado por el endoscopio. Además de suspender temporalmente las maniobras, se deberá aspirar lenta y paulatinamente el aire colectado. La aspiración súbita puede generar un cambio brusco en la capacidad distensible del tubo digestivo, agravando el estímulo vagal.

c. Estímulo por presencia. Es uno de los menos frecuentes pero de los más intensos, sucede por la sola presencia del endoscopio en el tubo digestivo, y en la mayoría de los casos será necesario retirar el endoscopio hasta que se controle farmacológicamente el estímulo vagal.

2. Inhibición del inhibidor. La estimulación vagal del corazón es mediada por receptores muscarínicos, así que la inhibición muscarínica (efecto anticolinérgico) revertirá la acción parasimpática inhibitoria del cronotropismo cardíaco. Existen diferentes tipos de anticolinérgicos, algunos de acción central y otros de acción periférica. El bromuro de butilhioscina es un derivado cuaternario de la hioscina que, a diferencia de la atropina, virtualmente no atraviesa la barrera hematoencefálica, por lo que no causa efectos en el sistema nervioso central ni en el músculo ciliar, pero actúa casi de inmediato (latencia 45 segundos) inhibiendo el efecto parasimpático depresor ${ }^{(14)}$. También reduce el estatus espasmódico del tubo digestivo por su acción anticolinérgica directa en el bloqueo ganglionar de las paredes viscerales. La butilhioscina se administra de $0.1-0.2 \mathrm{mg} / \mathrm{kg}$.

3. Estimulación del estimulante. Sólo en los casos en que el reflejo vagal es refractario a la administración de anticoli- nérgicos y la bradicardia pone en riesgo la vida, se puede administrar un estimulante del cronotropismo cardíaco mediado por los receptores $\beta 1$.

a. Aminas no catecolamínicas. La efedrina es un precursor de la descarga de noradrenalina desde las neuronas simpáticas, por lo tanto incrementa la frecuencia cardíaca por estimulación beta, pero también aumenta la postcarga y la presión arterial por estimulación alfa ${ }^{(15)}$. La efedrina se puede administrar en bolos de 100-200 $\mu \mathrm{g} / \mathrm{kg}$.

b. Aminas catecolamínicas. Por sus efectos arritmogénicos e isquémicos, la administración de aminas catecolamínicas (adrenalina $1 \mathrm{mg}$ en bolo) sigue siendo una opción sólo de emergencia.

\section{Hipotensión aguda}

La hipotensión aguda es una complicación frecuente en el paciente anestesiado para procedimientos endoscópicos. Recordando que la fórmula de la presión arterial es el resultado de la multiplicación del gasto cardíaco por las resistencias periféricas, las principales causas de la pérdida de la presión arterial deberán ser resultado de la alteración de alguna de las variables mencionadas en la fórmula. Durante la anestesia para procedimiento endoscópico y sin enfermedad agregada, las causas más frecuentes son:

1. Alteraciones en el gasto cardíaco. En condiciones normales, el gasto cardíaco es el resultado del volumen sistólico por la frecuencia cardíaca, las principales modificaciones en estos parámetros son:

a. Disminución del volumen sistólico. El propofol tiene un efecto inotrópico negativo mediado por una disminución en la recaptura del calcio por el retículo sarcoplásmico $^{(16)}$, la merma en la capacidad contráctil de la miofibrilla cardíaca disminuye su capacidad de expulsión volumétrica durante la sístole y por ende la disminución del gasto cardíaco.

b. Disminución en la frecuencia cardíaca. Como ya mencionamos, la estimulación cardíaca mediada por receptores muscarínicos disminuye su cronotropismo, dando como resultado su bajo gasto.

2. Alteraciones en las resistencias periféricas.

a. Vasodilatación directa por fármacos. De nueva cuenta la disminución de la recaptura del calcio mediada por propofol genera la pérdida de las resistencias periféricas.

b. Vasodilatación indirecta por fármacos. El aumento en la histamina plasmática tras la administración de opioides provoca una dilatación importante de las arteriolas terminales ${ }^{(17)}$. 


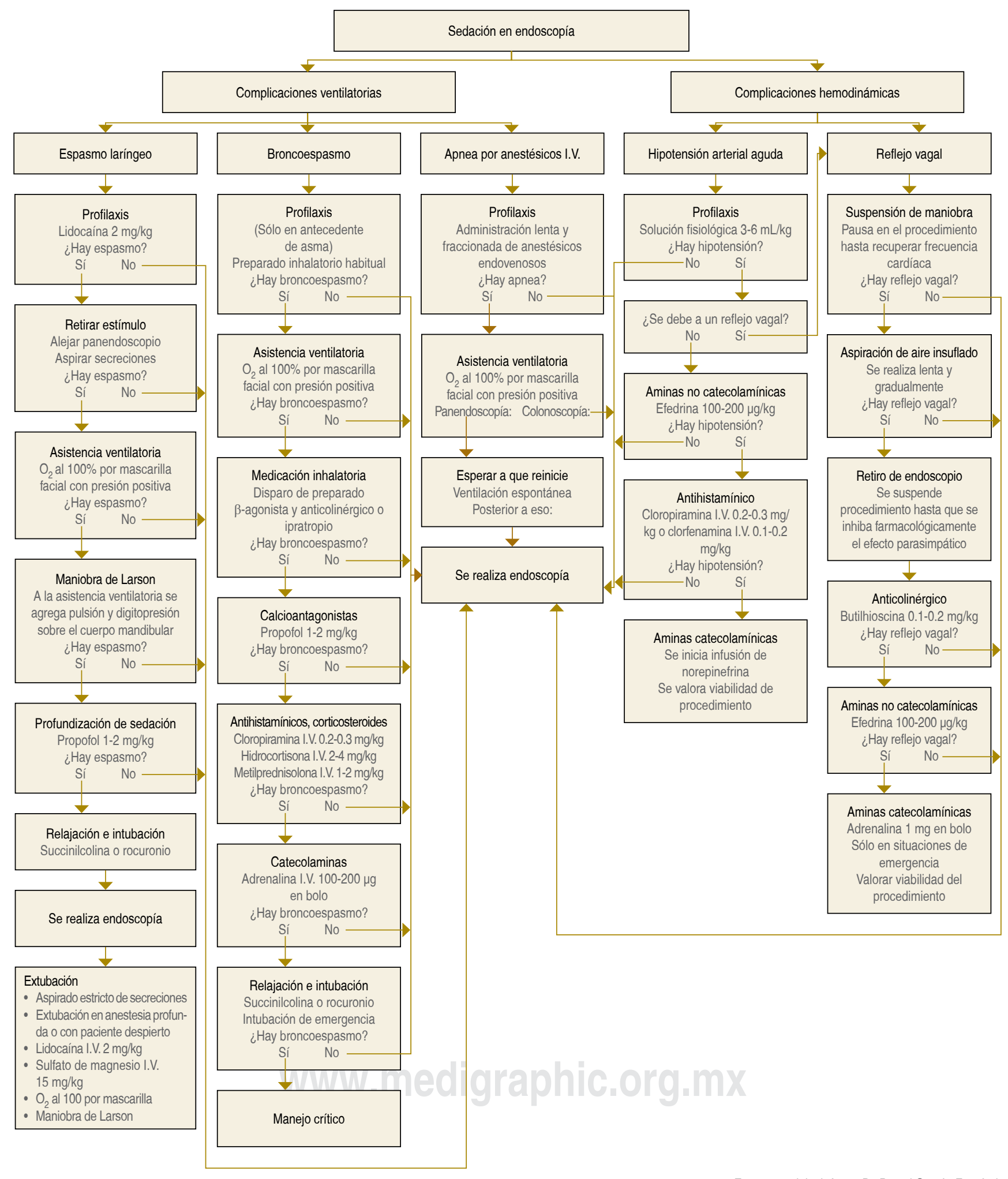

Esquema original. Autor: Dr. Baruvi Gaytán Fernández

Figura 1: Complicaciones ventilatorias y hemodinámicas frecuentes en la sedación para endoscopia diagnóstica del tubo digestivo en ausencia de enfermedad concomitante. 
Algunos otros fármacos de uso frecuente pueden causar alteraciones directas sobre el volumen sistólico, las resistencias periféricas o el gasto cardíaco en general. Los agonistas alfa-2 adrenérgicos como la dexmedetomidina, además de su acción sedante y analgésica, provee un efecto simpaticolítico por agonismo en la subunidad alfa2 -a ${ }^{(18)}$, el cual por sí mismo puede generar algún grado de bradicardia y vasodilatación periférica disminuyendo el gasto cardíaco y causando hipotensión aguda. Las benzodiacepinas hidrosolubles como el midazolam estimulan la unión del ácido gamma-aminobutírico (GABA) a la subunidad A de los receptores GABA, generando una acción inhibitoria de la actividad neuronal ${ }^{(19)}$, aunque las benzodiacepinas afectan dicha actividad a todos los niveles del neuroeje, no pueden emular los mismos grados de depresión neuronal que los inductores, por lo que sus efectos hemodinámicos son menores cuando se utilizan a dosis de ansiolítico sedante.

La hipotensión es un efecto secundario previsto al administrar anestésicos endovenosos (inductores, opioides, benzodiacepinas, agonistas alfa-2 adrenérgicos), siempre y cuando no descienda más del 30\% de su presión arterial basal o habitual. Si el descenso rebasa el margen descrito entonces ya no se define como efecto secundario y se considera una complicación.

La hipotensión aguda es una complicación muy relevante puesto que sus efectos se ven reflejados directamente en la perfusión sistémica, y ya que los órganos más susceptibles a la hipoperfusión son el corazón, el cerebro, el hígado y los riñones, es imperativo aplicar estrategias para su pronta corrección:

1. Profilaxis. La administración de anestésicos endovenosos generalmente ocasiona una descompensación entre el continente y el contenido hemodinámico, causado por una dilatación de mayor o menor grado del continente, por esta razón es conveniente aumentar preventivamente el contenido. Esto se puede lograr con la administración de solución salina fisiológica $(\mathrm{NaCl} 0.9 \%)$ de 3 a $6 \mathrm{~mL} /$ $\mathrm{kg}$ previo al inicio de la sedación.

2. Vasoconstricción directa. La mayoría de los efectos vasodilatadores directos de los anestésicos endovenosos se pueden contrarrestar con la estimulación adrenérgica alfa 1 agonista:

a. Noradrenalina endógena. Se puede estimular la hipersecreción de noradrenalina endógena con la administración de bolos de efedrina de 100-200 $\mu \mathrm{g} / \mathrm{kg}$. Generalmente las reservas de noradrenalina endógena se agotan después de la aplicación reciente del tercer bolo, por lo que la administración posterior de este fármaco tendrá un pobre o nulo efecto.

b. Noradrenalina exógena. Si la respuesta con efedrina no es la esperada, o hemos agotado los bolos efectivos de este fármaco, es recomendable el inicio de noradrenalina sintética en infusión, siempre y cuando se descarten otras causas de hipotensión, y en su caso, se erradique su génesis.

3. Vasoconstricción indirecta. Se deben contrarrestar los mecanismos de vasodilatación indirecta por fármacos como la liberación de histamina. En los casos en que se detecte la hipotensión causada por histamina, se puede utilizar clorhidrato de cloropiramina a $0.2-0.3 \mathrm{mg} / \mathrm{kg}$ o maleato de clorfenamina $0.1-0.2 \mathrm{mg} / \mathrm{kg}^{(17)}$. Si se inhibe farmacológicamente la vasodilatación indirecta, se generará un efecto indirecto de vasoconstricción.

Todas estas opciones terapéuticas se ordenan y esquematizan por prioridad y eficacia en la Figura 1, entendiendo que el éxito de una medida terapéutica suspende las consecuentes.

\section{CONCLUSIONES}

El manejo anestesiológico del paciente durante una endoscopía del tubo digestivo presenta retos, riesgos y complicaciones diferentes al paciente quirúrgico convencional, por lo tanto las guías y esquemas para solución de crisis también deben ser adecuadas en este sentido, adaptándolas a las nuevas técnicas de sedación en una época contemporánea donde el manejo del paciente fuera de quirófano es cada vez más frecuente.

En la mayoría de los tratados de anestesiología o en los artículos médicos provenientes del extranjero se mencionan tratamientos que pueden incluir medicamentos no disponibles en la República Mexicana; esto puede generar terapéuticas incompletas y frustración en el personal médico. Se deben ajustar las guías y los esquemas de tratamiento a los fármacos disponibles en nuestro país intentando un equilibrio entre la actualización académica continua pero sin ceder a la moda farmacéutica, que en algunos casos sólo incrementa costos sin ofrecer mejoría sobre los esquemas farmacológicos tradicionales.

Como quedó esquematizado en la Figura 1, la suspensión del procedimiento endoscópico no debe ser la primera opción ante la presencia de la mayoría de las complicaciones ventilatorias y/o hemodinámicas, ya que existe una amplia gama de estrategias que pueden solucionar la complicación y dar viabilidad al procedimiento. 


\section{REFERENCIAS}

1. Ikari T, Sasaki CT. Glottic closure reflex: control mechanisms. Ann Otol 1980;89:220-224.

2. De Riva N, Valero R, Gomar C. La vía aérea superior. En: Carrero E, Castillo J, Villalonga A, editores. Fisiología aplicada a la anestesiología $3^{a}$ edición. Madrid: Ergon; 2012:397-401.

3. Feldman MA, Patel A. Anestesia para la cirugía oftálmica y otorrinolaringológica. En: Miller RD, editor. Miller anestesia séptima edición. Barcelona: Elsevier; 2010:2123-2154.

4. Bittner EA, Grecu L, George E. Complicaciones posoperatorias. En: Longnecker DE, Brown DL, Newman MF, editores. Anestesiología. México, D.F.: McGraw-Hill; 2010:1700-1715.

5. Gray H. Extubation. En: Calder I, Pearce A, editores. Core topics in airway management. Cambridge University Press: Cambridge; 2005:87-92.

6. Goodman NW, Black AM, Carter JA. Some ventilatory effects of Propofol as sole anaesthetic agent. Br J Anaesth. 1987;59:1497-1503.

7. Reves JG, Glass PSA, Lubarsky DA. Anestésicos intravenosos. En: Miller RD, editor. Miller Anestesia séptima edición. Barcelona: Elsevier; 2010:485-534.

8. Pinto-Pereira LM, Orrett A, Balbirsingh M. Physiological perspectives of therapy in bronchial hyperreactivity. Can J Anaesth. 1996;43:700-713.

9. Prakash YS, Kannan MS, Walseth TF, et al. Role of cyclic ADP ribose in the regulation of $[\mathrm{Ca} 2+] . \mathrm{i}$ in porcine tracheal smooth muscle. Am J Physiol Cell Physiol. 1998;274:1653-1660.

10. Expert Panel Report 3 (EPR-3). Guidelines for the diagnosis and management of asthma-summary report. J Allergy Clin Immunol. 2007;120:94-138.
11. Blunk JA, Schmelz M, Zeck S, et al. Opioid-induced mast cell activation and vascular responses is not mediated by $\mu$-opioid receptors: an in vivo microdialysis study in human skin. Anesth Analg 2004;98:364-370.

12. Nagele $P$, Hüpfl $M$. Anestesia en urgencias prehospitalarias y en la asistencia traumatológica. En: Miller RD, editor. Miller Anestesia séptima edición. Barcelona: Elsevier; 2010:2079-2098.

13. Brown RH, Greenberg RS, Wagner EM. Efficacy of propofol to prevent bronchoconstriction: effects of preservative. Anesthesiology. 2001;94:851-855

14. Vickers MD, Morgan M, Spencer PSJ, et al. Agonistas parasimpáticos y agentes anticolinérgicos. En: Fármacos en anestesia y cuidados intensivos octava edición. México D.F.: Prado; 2002:417-427.

15. Vickers MD, Morgan M, Spencer PSJ, et al. Fármacos utilizados por sus efectos sobre el tono vascular y la contractilidad cardíaca. En: Fármacos en anestesia y cuidados intensivos octava edición. México D.F.: Prado; 2002:429-510.

16. Vargas-Trujillo C. Disfunción diastólica con anestésicos y cardioprotección con halogenados. Rev Mex Anest. 2012;35:S46-S55.

17. Fukuda K. Opioides. En: Miller RD, editor. Miller anestesia séptima edición. Barcelona: Elsevier; 2010:535-590.

18. Carrillo-Torres O, Pliego-Sánchez MG, Gallegos-Allier MM, et al. Utilidad de la dexmedetomidina en diversos contextos en la medicina actual. Rev Mex Anest. 2014;37:27-34.

19. Martínez-Bazán Y, Ferrera-Ches NJ, Ortiz-Sánchez Y, et al. Medicación preanestésica con midazolam/paracetamol oral vs midazolam intramuscular en amigdalectomía. Anestesia en México 2016;28:22-31. 